\title{
The interaction of legal and social norm enforcement ${ }^{\dagger}$
}

\author{
Sebastian Kube* and Christian Traxler*
}

This Version: September 22, 2009

\begin{abstract}
Although legal sanctions are often non-deterrent, we frequently observe compliance with 'mild laws'. A possible explanation is that the incentives to comply are shaped not only by legal but also by social sanctions. This paper employs a novel experimental approach to study the link between legal and social norm enforcement. We analyze whether the two institutions are complements or substitutes. Our results show that legal sanctions partially crowd-out social norm enforcement. The welfare effect from mild laws is positive, however, as a higher level of compliance is achieved at lower enforcement costs.
\end{abstract}

JEL classification: K42; C9

Keywords: social sanctions, legal sanctions, norm enforcement, mild laws, laboratory experiment, VCM, public goods.

\footnotetext{
${ }^{\dagger}$ We would like to thank participants at the PET Workshop on "Public Economics: Theoretical and Experimental Approaches" in Lyon and seminar participants in Bonn for helpful comments and suggestions. Georg von Heusinger provided excellent research assistance.

*Max Planck Institute for Research on Collective Goods, Germany. email:[lastname]@coll.mpg.de
} 


\section{Introduction}

Societies have come up with laws to regulate many situations in economic and societal life where individual and social interests are in conflict (environmental laws, tax laws, etc.). While these laws are usually backed by legal sanctions, potential offenders often face rather low detection risks and relatively mild sanctions. Legal norm enforcement is then non-deterrent, in the sense that rational individuals with reasonable degrees of risk aversion should be expected to deviate from the law. Nevertheless, we frequently observe widespread compliance with 'mild laws'. ${ }^{1}$ One explanation put forward by legal scholars is that the incentive to comply with the law not only derives from formal law enforcement, but also "from the informal enforcement of social mores by acquaintances, bystanders, trading partners, and others" (Ellickson 1998, p.540). Traxler and Winter (2009) provide survey evidence which supports this reasoning. They show that a substantial fraction of the population is willing to impose sanctions (disapproval or social exclusion) on individuals who are, e.g., drunk driving, fare dodging or cheating on taxes. The importance of such decentralized, social sanctions for the enforcement of compliance is documented in a rapidly growing body of literature. $^{2}$ However, a key question is still left unanswered by this literature: how does formal law enforcement affect the informal enforcement of norms? Are these two enforcement institutions substitutes or complements, i.e., do centralized legal sanctions crowd out or crowd in decentralized social sanctions?

Ideally, these questions would be studied in a natural environment. As the introduction of or the change in legal regulations is typically endogenous, it would be extremely difficult to identify the causal link between legal and social norm enforcement from field data. Moreover, there are obvious constraints in the measurement of social sanctions. To avoid these empirical limitations, our study builds on a simple and parsimonious laboratory experiment. This allows us to assess our research questions in a controlled environment. In the experiment, subjects in groups of four play a one-shot public-goods game in which they face a voluntary-contribution mechanism. Our baseline treatment (BASE) captures a situation in which only social sanctioning is possible while legal sanctions are absent. Players observe each others' contributions to the public good and can assign

\footnotetext{
${ }^{1}$ See, e.g., Becker (2007) on tax evasion and Cohen (2000) on the enforcement of environmental regulations. A general discussion is provided by Tyran and Feld (2006) and Galbiati and Vertova (2008a).

${ }^{2}$ Seminal experimental studies are Fehr and Gächter (2000), Masclet et al. (2003). For a law and economics treatment of social sanctions see Posner (2000). For a theoretical contribution see, e.g., Rege (2004).
} 
costly punishment points which reduce the payoff of the punished player (Fehr and Gächter 2002, Herrmann et al. 2008). In addition to these decentralized sanctions, the second treatment (LAW) introduces legal sanctions. The law imposes sanctions on deviations from the socially optimal contribution level. More specifically, players are randomly monitored after their contribution and sanctioning decisions. A player who is detected contributing less than the social optimum is fined by a central punishment authority - independently of any social sanctions incurred. Comparing subjects' sanctioning behavior between the two treatments then allows us to analyze the impact of centralized sanctions on social norm enforcement in a controlled set-up.

The impact of legal on social sanctions can be decomposed into a direct and an indirect effect, where the latter is linked to the actual compliance level. Presumably, compliance, i.e., the level of individuals' contributions, is sensitive to the treatment conditions: one might expect contributions to be higher when subjects face the risk of social versus the risk of social cum legal sanctions. As a consequence, differences in punishment choices might be due to the change in contributions rather than the introduction of legal sanctions per se. To disentangle direct and indirect treatment effects, we developed a method in the spirit of Selten's (1967) strategy method. In particular, we implement a novel strategy method at the punishment stage of the public-goods game. ${ }^{3}$ After their contribution choice, players are confronted with a series of different triples of other group members' contributions. One of these triples covers the others' actual contributions, while the remaining ones are hypothetical situations. Subjects have to make punishment decisions in each situation, knowing that only the decisions for the actual contribution triple will be payoff-relevant - of course, without knowing which one this actually is.

This new method has several advantages. First of all, it assures that contribution-situations are virtually constant between treatments. Hence, we can measure the direct impact of legal sanctions on individuals' sanctioning behavior (keeping constant others' contribution levels). Second, we observe a series of individual's punishment decisions for truly exogenous contributions rather than single punishment choices that follow endogenous contribution choices. Exposing players to randomly varied contribution triples, we can also analyze the causal effect of others' contribution levels and composition (e.g., facing a group of one high and two low contributions as compared to three intermediate contributions) on the extent of punishment.

\footnotetext{
${ }^{3}$ Fischbacher et al. (2001) and Fischbacher and Gächter (2009) use strategy methods at the contribution stage of public good games. For a related application in prisoners' dilemma-experiments, see Falk et al. (2005).
} 
Our experiment points out several results. First of all, comparing the punishment behavior in treatment BASE to previous studies on decentralized punishment reassures that our novel strategymethod approach does not affect or bias subjects' behavior in a systematic, unpredicted way. In line with the existing literature, we observe that a large fraction of the population engages in decentralized norm enforcement. Typically, subjects sanction those individuals who contribute less than themselves, with the sanctioning intensity increasing in the difference in contributions. Moreover, our data reveal that the punishment incurred by an individual crucially depends on the contributions of the other group members. Everything else being equal, individuals assign stricter sanctions to a free-rider the higher the contributions of the unaffected players in the group are.

This pattern of social norm enforcement is prevalent in both treatments. In the LAW treatment, however, decentralized sanctioning is significantly less intense: the presence of legal sanctions partially crowds out the social norm enforcement. The decline in sanctions is particularly pronounced when the difference between punisher's and punishee's contribution is large. Our data further show that actual contributions are nevertheless higher in the LAW treatment. The combination of legal and social sanctions thus produces more pro-social behavior than the decentralized enforcement on its own. As long as the centralized enforcement system comes at reasonable costs, the increase in cooperation is achieved at lower overall costs of legal and social sanctioning. Compared to an 'archaic world' where only decentralized punishment is possible, the introduction of mild laws therefore gives rise to a substantial welfare gain.

To the best of our knowledge, we are the first to present clear-cut evidence on the interaction of legal and social sanctions. While the importance of the interplay between the two sanctioning institutions is generally acknowledged among lawyers and economists, practitioners and theorists likewise (Ellickson 1998, Falk et al. 2005, Meares et al. 2004), up to now both have only been studied in isolation. Decentralized sanctions are discussed in a large body of mainly experimental literature, showing that many subject are willing to forego personal profits to punish anti-social behavior. ${ }^{4}$ Although social sanctions help to overcome the free-rider problem, an increased level of cooperation is usually accompanied by significant efficiency losses caused by the cost of social sanctioning (at least in the short run, see Gächter et al. 2008).

\footnotetext{
${ }^{4}$ See, e.g., Fehr and Gächter 2000, 2002, Masclet et al. 2003, Gürerk et al. 2006, Carpenter 2007, Nikiforakis and Normann 2008.
} 
A smaller strand of experimental studies considers centralized sanctions in isolation. Tyran and Feld (2006), Galbiati and Vertova (2008a, 2008b), Hörisch and Strassmair (2008), and Kosfeld et al. (2009) explore if, respectively when and why legal sanctions influence compliance. In line with economic theory, they typically find that strong (deterrent) centralized sanctions are effective in enforcing compliance - in particular, if they emerge endogenously via, e.g., voting. Galbiati and Vertova demonstrate that even non-deterrent sanctions might foster compliance. Their results suggest that mild laws serve as coordination devices, shaping beliefs about others' behavior and therewith the degree of cooperation in the short-run. However, Galbiati and Vertova (2008a) also show that mild laws per se are not sufficient to establish norm-compliance in the long-run. Our study, which is the first to combine the analysis of centralized and decentralized sanctioning, suggests that the combination of social and mild legal sanctions - as proposed by Ellickson (1998) - might be successful in achieving compliance with mild laws.

\section{The Experiment}

To assess the impact of legal on social sanctions, we consider a situation with scope for social norm enforcement. Players are randomly matched into groups of $n=4$ and play a public-goods game at stage I. Each player $i \in\{1 . .4\}$ has to decide how many tokens $c_{i}$ of his initial endowment $E=20$ to contribute to a joint project (the public good), and how many to keep for himself. Each token allocated to the public good increases the payoff of each player in the group by $\alpha c_{i}$, with the marginal per capita return $\alpha=0.4$. The primary individual payoff $\pi_{i}^{I}$ is then given by $\pi_{i}^{I}=E-c_{i}+\alpha \sum c_{j}$. As $\partial \pi_{i}^{I} / \partial c_{i}=-1+\alpha<0$, each player has the dominant strategy to free-ride on others' contributions. The unique Nash equilibrium therefore is to keep the entire endowment $E$. However, since $1 / n<\alpha$, it is socially optimal if all players would contribute their entire endowment to the public good. Players thus face a social dilemma: individuals' and group's interests are in conflict and free-riding can be considered as anti-social behavior. Society may want to regulate the dilemma by establishing a centralized norm enforcement institution ('law', 'police'), that imposes sanctions on free-riders. In addition, sanctions may also be imposed in a decentralized way.

To account for centralized and decentralized sanctioning institutions, we add two additional stages to the game. At stage II, players observe each others' contribution and can then decide to 
impose social sanctions by assigning up to 10 punishment points to each player. Each punishment point $d_{i j}$ costs the punisher $i$ one token while at the same time it reduces the punished player $j$ 's payoff by three tokens (Fehr and Gächter 2002). The individual payoff from stage II is thus given by $\pi_{i}^{I I}=-\beta \sum_{j \neq i} d_{i j}-\gamma \sum_{j \neq i} d_{j i}$ (with $\beta=1$ and $\gamma=3$ ). In this situation, social sanctions constitute a second-order public good. While everyone would be better of if free-riding is credibly sanctioned (such that the social first-best is achieved without any actual punishment), individually each player has a dominant strategy not to invest into sanctioning at stage II. To see why, let us assume that at stage I all players would anticipate to be sanctioned if $c_{i}<E$, and that they expect a sanctioning pattern to be such that $\partial\left(\pi_{i}^{I}+\pi_{i}^{I I}\right) / \partial c_{i}<0$. Rational players would then choose $c_{i}=E$. However, the corresponding beliefs cannot be part of a Baysian Nash equilibrium, since $\partial \pi_{i}^{I I} / \partial d_{i j}=-\beta<0$.

Finally, at stage III, legal sanctions are implemented as a stochastic payoff. A player is monitored with a fixed probability $p=1 / 8$. In this case, he faces a fine which is proportional to the deviation from the contribution level that is prescribed by the law, $L=E=20$, such that his expected payoff from stage III becomes $\pi_{i}^{I I I}=-p s\left(L-c_{i}\right)$, with $s=1.2$. The expected payoff from all three stages is given by

$$
\Pi_{i}=\underbrace{E-c_{i}+\alpha \sum_{j=1}^{4} c_{j}}_{\pi_{i}^{I}}-\underbrace{\beta \sum_{j \neq i} d_{i j}-\gamma \sum_{j \neq i} d_{j i}}_{\pi_{i}^{I I}}-\underbrace{p s\left(L-c_{i}\right)}_{\pi_{i}^{I I I}}
$$

Our choice of parameters implies that legal sanctions in isolation are 'non-deterrent', in the sense that contributing zero is still the dominant (expected-payoff maximizing) strategy: $\partial\left(\pi_{i}^{I}+\right.$ $\left.\pi_{i}^{I I I}\right) / \partial c_{i}=-1+\alpha+p s<0$. Our design therefore provides a scenario in which social sanctions can potentially help to achieve compliance with a mild law.

Note that we implement a sequence where social sanctions are applied before potential legal sanctions take place. This sequence not only appears to be natural for many situations (consider, for instance, the case where a partner learns about the spouse's income tax evasion prior to tax authorities). One might also argue that it is a harder test for observing an interaction between legal and social sanctions. If crowding-effects occur in the sequence implemented here, we conjecture the effect to be even stronger if we would use the opposite order. The confirmation of the hypothesis is left for future research. 
Treatments The experiment implements two treatment conditions. Treatment BASE consists of stages I and II only. Hence, free-riders only face the threat of social sanctions. In treatment LAW, we additionally include the third stage with legal sanctions. Comparing behavior between these two treatments allows us to observe individuals' sanctioning behavior $d_{i j}$ in the presence and absence of legal sanctions. As noted earlier, individual sanctioning decisions are measured using a strategy method. At stage II of both treatments, each subject $i$ faces 11 contributiontriples $\left\{c_{j}^{t}, c_{k}^{t}, c_{l}^{t}\right\}, t \in[1,11]$ (with the subindices $j \neq i, k \neq i, l \neq i$ denoting the other subjects hypothetical contributions). The order of these triples is randomized for each subject. One of the triples covers the actual contributions of the other players in the matching group. The remaining ten triples are hypothetical combinations of contributions, each being randomly drawn from a pre-defined set of combinations. ${ }^{5}$ For each contribution triple, subjects have to decide how many punishment points (if any) they want to allocate; knowing that 10 out of the 11 situations are hypothetical. It is also common knowledge that only the decisions made in the actual contributiontriple are payoff-relevant - without knowing which one is the 'real' triple, of course. In this way, we collect data from $3 \times 11$ sanctioning choices for each subject. The procedure assures that the hypothetical contribution-situations are exogenous and orthogonal to our treatments. By comparing the punishment decisions between LAW and BASE made for the ten hypothetical cases, we can therefore identify the ceteris paribus impact of the legal system on individuals' social sanctioning behavior (i.e., keeping constant the other player's contributions).

Predictions Let us now discuss different predictions regarding the treatment's impact on social sanctioning. The benchmark for the rational (and risk-neutral) self-interested player is straightforward. As illustrated above, social norm enforcement is a second-order public good and standard theory predicts zero sanctioning in both treatments. Given the overwhelming empirical evidence, however, we know that subjects do make use of their punishment option (see Nikiforakis and Normann 2008 for a recent survey). Social-preference models, surveyed in Fehr and Schmidt

\footnotetext{
${ }^{5}$ The following procedure was used. First, we defined three sets of contributions (low, intermediate and high): $c^{L} \in\{0, \ldots, 4\}, c^{M} \in\{5, \ldots, 15\}, c^{H} \in\{16, \ldots, 20\}$. Within each of the combinations, $\left\{c^{L}, c^{L}, c^{L}\right\},\left\{c^{L}, c^{L}, c^{M}\right\}$, $\left\{c^{L}, c^{L}, c^{H}\right\},\left\{c^{L}, c^{M}, c^{M}\right\},\left\{c^{L}, c^{M}, c^{H}\right\},\left\{c^{L}, c^{H}, c^{H}\right\},\left\{c^{M}, c^{M}, c^{M}\right\},\left\{c^{M}, c^{M}, c^{H}\right\},\left\{c^{M}, c^{H}, c^{H}\right\},\left\{c^{H}, c^{H}, c^{H}\right\}$, we randomly generated 8 different contribution triples by sampling with replacement from the corresponding sets $c^{L}, c^{M}$ and $c^{H}$ (see Appendix I). E.g., a subject might face $\{0,2,3\}$ for the combination $\left\{c^{L}, c^{L}, c^{L}\right\}$ and $\{1,2,10\}$ for $\left\{c^{L}, c^{L}, c^{M}\right\}$, etc. Another subject might face $\{1,3,3\}$ for the former and $\{0,2,14\}$ for the later. If the set $\{0,2,14\}$ would by chance correspond to the real triple, the subject would not face this situation but instead another one of the pre-defined contribution triples for $\left\{c^{L}, c^{L}, c^{M}\right\}$ would be randomly selected.
} 
(2006), are able to account for this behavior. These models, in particular the consequentialist theories, predict that the introduction of legal sanctions crowd out social sanctions.

The intuition behind this prediction is best illustrated within the framework of inequality aversion (Fehr and Schmidt 1999), where punishment is motivated by the disadvantageous inequality experienced by the punisher. Legal sanctions clearly reduce the payoff inequality that a compliant contributor $i\left(c_{i}=20\right)$ experiences with respect to a free-rider $j\left(c_{j}=0\right)$. Without legal sanctions the difference in $\pi^{I}$ would be $c_{i}-c_{j}=20$ token; with legal sanctions, the expected gap in $\left(\pi^{I}+\pi^{I I I}\right)$ equals $\left(c_{i}-c_{j}\right)(1-p s)=17$ token. ${ }^{6}$ By mitigating the payoff inequality that arises from free-riding, the centralized sanctions reduce the extent of decentralized sanctions imposed by an inequality-averse player. Hence, legal sanctions should partially replace social sanctions.

A different strand of literature has emphasized the role of emotions, in particular anger, in motivating individuals' sanctioning behavior (Bosman and van Winden 2002, Hopfensitz and Reuben 2009). Along these lines, the introduction of the legal system could also crowd out social punishment, if the anticipation of legal sanctions reduces the punisher's emotional drive to impose social sanctions on the free-rider. One might argue, however, that the strategy method used in our approach alters the subjects' emotional states and induces more 'cold' decision making at the sanctioning stage. We might therefore observe a lower level of punishment than in the case of unconditional punishment decisions. ${ }^{7}$ As we apply the strategy method in all treatments, this should not have an impact on treatment differences.

Finally, one can derive an alternative prediction regarding the treatment effect from legal theories. In particular, expressive theories of law (Cooter 1998, McAdams 2000) suggest that the introduction of a legal system will shape player's perceptions on what is 'good' and 'bad' conduct. In turn, we should observe that players coordinate on imposing more sanctions on those who more clearly deviate from the legal norm, $L=20$. Legal sanctions should therefore crowd in social sanctions for low contribution levels.

\footnotetext{
${ }^{6}$ Trautmann (2009) explores the case of inequality aversion under risky payoffs. Following the proof of proposition 5 in Fehr and Schmidt (1999), one can easily show that the punishment pattern supporting an equilibrium $c_{i}^{*}=c_{j}^{*} \in[1,20]$ is given by $d_{i j}=\left(c_{i}^{*}-c_{j}\right)(1-p s) / \mu$ (where $\mu$ captures the exogenous distribution of preference types and the punishment costs $\beta$ and $\gamma$ ). Hence, social sanctions are decreasing in $p s$. Note that this observation applies to any of the multiple equilibria that can emerge.

${ }^{7}$ Note, that a number of studies (e.g., Brandts and Charness 2000) did not find significant differences in behavior between strategy and direct response methods in other contexts.
} 
Implementation The computerized experiments (using z-Tree; Fischbacher 2007) were run in March 2009 in Bonn. 96 students from all majors were randomly recruited (using Orsee; Greiner 2004) and participated in one of the two treatment sequences displayed in Table 1. After subjects arrived in the lab, they were randomly and anonymously allocated into matching groups. Subjects then received a written copy of the instructions for the first treatment. Additionally, in order to create common knowledge about the instructions, we read them out aloud. The instructions and the information on the computer screens were written in a neutral language, omitting words like punishment, sanctions, or law to avoid framing and demand effects. Before the experiment started, subjects had to answer a set of control questions to make sure that they understood the rules of the game. ${ }^{8}$ After they finished the first treatment, subjects were told that they would now participate in a second treatment. They did not receive any feedback about their payoffs or the others' actual contribution choices from the first treatment. After playing the alternative treatment, which followed the same procedure as before, subjects received feedback about the outcomes of both treatments. Thereafter, they had to fill out a short questionnaire asking, e.g., for socio-economic data. An entire session lasted approximately 60 minutes. Subjects were paid according to their cumulated period payoffs at a rate of 20 Cent per tokens. Participants earned about 13 Euros on average, including a show-up fee of four Euros.

Table 1: Design Summary

\begin{tabular}{|c|c|c|c|}
\hline & $1^{\text {st }}$ Treatment & & $2^{\text {nd }}$ Treatment \\
\hline Sequence $1(n=48)$ : & BASE & $\rightarrow$ & LAW \\
\hline Sequence $2(n=48)$ : & LAW & $\rightarrow$ & BASE \\
\hline
\end{tabular}

Notes: The table displays the treatment order in both sequences. Sequence 1 captures the introduction of a mild law into a society which is initially governed by decentralized norm enforcement. Sequence 2 starts from a situation with legal and social norm enforcement, and then removes the centralized punishment institution.

\footnotetext{
${ }^{8}$ Two subjects, one in each treatment, had substantial problems understanding the game. They repeatedly failed to answer the control questions. As we did not want to embarrass them in front of the other students, we let them take part in the experiment but excluded their data from the analysis. This can be further motivated by the fact that these two assigned $635 \%$ (444\%) more punishment points than the median (average) of the remaining subjects. The results presented in the following section are robust to excluding the two groups of the two 'drop-out' subjects.
} 


\section{Results}

This section presents the results from the experiment. Our main focus is on the impact of legal on social sanctions. Moreover, we analyze cooperation and the overall welfare effect from mild laws. We first present the findings from the between-subject comparison. These results are corroborated by the within-subject comparison, which is presented thereafter.

\subsection{Between-subject comparison}

Legal and social sanctions First, we consider the direct impact of legal on social sanctions. Below we will show that subjects' actual contributions are endogenous to our treatment conditions. To identify the direct treatment effect, we therefore focus on subjects' punishment decisions for the 10 hypothetical contribution triples. ${ }^{9}$ As these triples are - in expectation terms - the same between treatments, we can assess the direct impact from the treatment manipulation, i.e., holding constant the contributions that the punishers face.

In line with the existing literature discussed above, we observe a substantial amount of social sanctions. Figure 1 displays the sanctioning pattern by comparing the mean amount of punishment (on the vertical axis) for different gaps $c_{i}-c_{j}$ in public-good contributions between punisher $i$ and punishee $j$ (horizontal axis). The figure reveals that sanctions are literally social in both treatments, in the sense that they are mainly targeted at free-riders: subjects impose sanction on those players who contributed less than they themselves did, with the sanctioning intensity being increasing in the inequality in contributions. In contrast, anti-social punishment (see Herrmann et al. 2008), i.e., sanctions targeted at contributors where $c_{i}-c_{j}<0$, is rarely observed in either treatment (which is why Figure 1 groups those observations in the bar for $(-2,-20]$ ). As is clearly visible from Figure 1, social sanctioning is less intense in LAW than in BASE. While the treatment effect is small for minor 'offenses', the decline in sanctions is particularly pronounced when the difference between $c_{i}$ and $c_{j}$ is large, i.e., when the degree of 'non-compliance' - and thus the expected legal sanction - is high. This provides some first, indicative evidence that legal sanctions tend to crowd out social sanctions.

Averaging over all players and all hypothetical situations, the number of assigned punishment points $d_{i j}$ is $18 \%$ lower in LAW then in BASE, dropping from .84 down to .69 points. However, a

\footnotetext{
${ }^{9}$ Including the real contribution triple does not change any of the following results.
} 
Figure 1: Mean Punishment Patterns

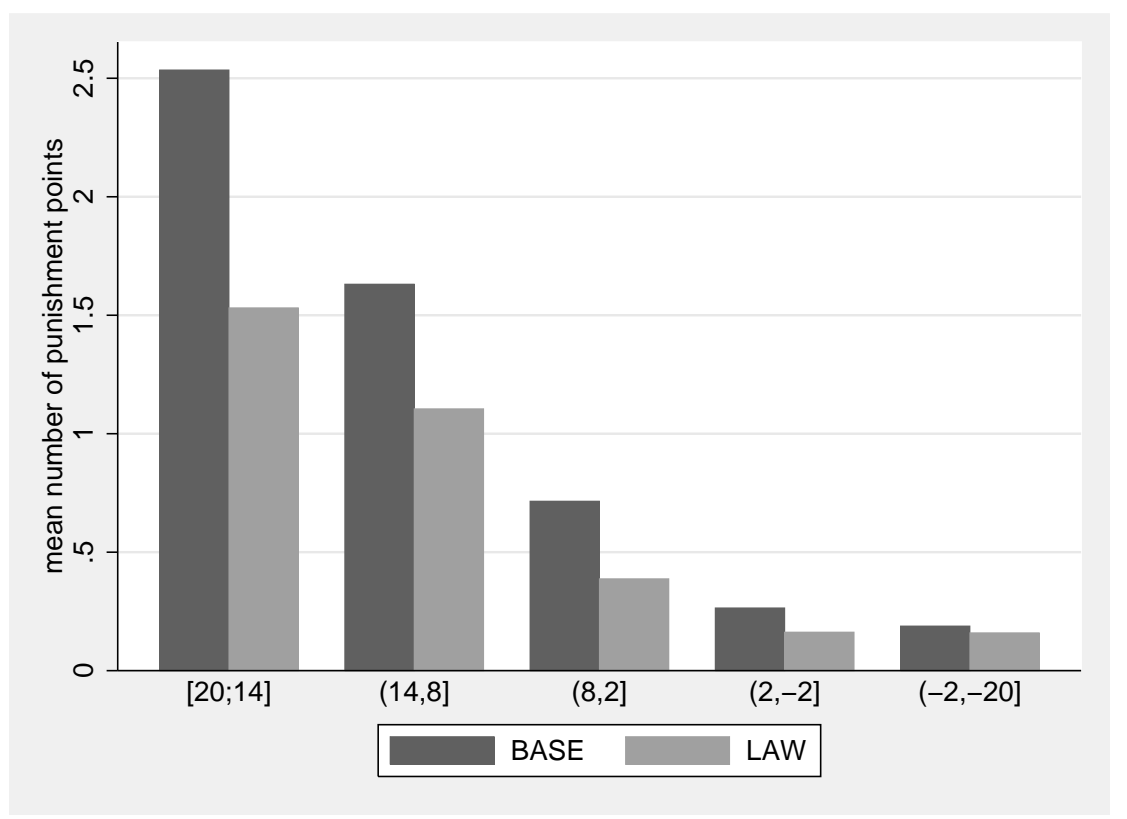

non-parametric test reveals no significant difference (rank-sum test, comparing the mean number of punishment points assigned over all hypothetical situations per subject, $p=.528$, two-sided). The reason is likely to be that those observations with small differences $c_{i}-c_{j}$, where there is hardly any punishment in either treatment, are substantially over-represented. Put differently, averaging over all contribution situations neglects that punishment choices and the treatment effect seems to depend, among other things, on the gap in $i$ and $j$ 's contributions. In order to control for $c_{i}$ and $c_{j}$, we conduct a regression analysis. Making use of the panel structure of our data (recall that for each subject we observe $3 \times 10$ sanctioning decisions for exogenous triples) and accounting for $0 \leq d_{i j} \leq 10$, we estimate a random-effects Tobit model. Since each subject faced different contribution triples in a random order, we also control for the sequence of triples $(t)$. Furthermore, we also control for contributions of the other, unaffected, group members $\left(c_{k, l}=\left(c_{k}+c_{l}\right) / 2\right)$.

Estimation results are presented in Table 2. The specification from Column (1) replicates the non-parametric test result. The treatment on its own does not reach statistical significance (even with a control for potential sequence effects). Test statistics indicate a very poor performance of this first estimation: the null hypothesis that all regressors are equal to zero cannot be rejected $(p=.284)$, suggesting that the specification is missing crucial explanatory variables. The picture changes substantially once we account for the gap in the punisher's and the punishee's (hypo- 
Table 2: Random-effects Tobit regression: Marginal effects on social sanctions

\begin{tabular}{|c|c|c|c|c|}
\hline \multicolumn{5}{|c|}{ Dependent variable: $d_{i j}$} \\
\hline & (1) & $(2)$ & $(3)$ & (4) \\
\hline LAW & $\begin{array}{l}-0.097 \\
(0.158)\end{array}$ & $\begin{array}{c}-0.279^{*} \\
(0.148)\end{array}$ & $\begin{array}{c}-0.284^{*} \\
(0.149)\end{array}$ & $\begin{array}{c}-0.275^{*} \\
(0.151)\end{array}$ \\
\hline$c_{i}-c_{j}$ & & $\begin{array}{c}0.064^{* * *} \\
(0.004)\end{array}$ & $\begin{array}{c}0.067^{* * *} \\
(0.004)\end{array}$ & $\begin{array}{c}0.067^{* * *} \\
(0.004)\end{array}$ \\
\hline$\left(c_{i}-c_{j}\right) \times L A W$ & & & & $\begin{array}{c}-0.001 \\
(0.004)\end{array}$ \\
\hline$c_{k, l}$ & & & $\begin{array}{c}0.012^{* * *} \\
(0.002)\end{array}$ & $\begin{array}{c}0.012^{* * *} \\
(0.002)\end{array}$ \\
\hline$t$ & $\begin{array}{l}-0.008 \\
(0.005)\end{array}$ & $\begin{array}{l}-0.003 \\
(0.004)\end{array}$ & $\begin{array}{l}-0.003 \\
(0.004)\end{array}$ & $\begin{array}{l}-0.003 \\
(0.004)\end{array}$ \\
\hline Log-likelihood & -3057 & -2443 & -2428 & -2428 \\
\hline Observations & 2820 & 2820 & 2820 & 2820 \\
\hline
\end{tabular}

Notes: The table displays the marginal effects evaluated at the mean (conditional on being uncensored) from random effects Tobit regressions. The dependent variable is the number of punishment points assigned from $i$ to $j, d_{i j}$. The sample covers all punishment choices for hypothetical triples in the initial treatment (see Table 1). The treatment dummy LAW equals unity in treatment LAW and zero otherwise. Variable $c_{i}-c_{j}$ measures the gap between punisher's and punishee's contributions. Variable $c_{k, l}=\left(c_{k}+c_{l}\right) / 2$ measures the average (hypothetical) contribution of the two other, unaffected, group members. $t$ depicts the sequence of triples. Estimation output for the constant is omitted and standard errors are in parentheses. Level of significance: ${ }^{*} p<0.1,{ }^{* *} p<0.05,{ }^{* * *} p<0.01$.

thetical) contributions, $c_{i}-c_{j}$. Column (2) shows a highly significant effect of this gap. The positive coefficient indicates that subjects impose more punishment points the larger the difference between the own and the other's contributions. ${ }^{10}$ At the same time, the estimated treatment effect becomes significant at a 10\%-level. Moreover, the log-likelihood of the specification increases dramatically. In Column (3) we additionally account for the mean contribution of the other two group members. Again, we obtain a significantly negative estimate for the treatment effect that is close to the 5\%-level. Hence, including legal sanctions reduces the extent of social sanctions. The estimates suggest that individuals on average allocate 0.28 punishment points less when a mild law is in place. To compare the effect size, note that free-riding by one additional token (a ceteris paribus decline in $c_{j}$ of one token) reduces the sanctioning that player $i$ imposes on $j$ by only 0.06 points. This indicates that the decline in social sanctioning in the LAW treatment is non-negligible. Furthermore, note that there is a significantly positive effect from $c_{k, l}$. Keeping contributions of players $i$ and $j$ fixed, an increase in average contributions of the unaffected group members thus

\footnotetext{
${ }^{10}$ Equivalent results are obtained if one includes $c_{i}$ and $c_{j}$ separately in the regression.
} 
results in stronger sanctions for player $j$. Quantitatively, however, the contribution level of $c_{k, l}$ is substantially less important for the punishment choice of $i$ than the direct comparison between $c_{i}$ and $c_{j}$.

Specification (4) explores whether there is an interaction between the treatment dummy and the extent of free-riding, $\left(c_{i}-c_{j}\right) \times L A W$. The estimation clearly neglects this conjecture. This means that the decentralized punishment of free-riding on the margin, i.e., the amount of sanctions that player $i$ imposes on $j$ if the latter reduces $c_{j}$ by one unit, remains constant between treatments. While marginal social sanctions remain constant, adding the legal sanctions in treatment LAW, increases the expected marginal punishment by $p s$ (see equation 1 ). The marginal overall sanctions - social cum legal - are thus higher in LAW than in BASE. This suggest that, despite a partial crowding-out of decentralized punishment by centralized sanctions, there are stronger incentives for cooperation under the mild law. ${ }^{11}$

Summarizing the first set of results on the direct impact of legal on social sanctions, we have found a negative treatment effect from $L A W$. The presence of the legal system reduces individuals' sanctioning behavior. Legal norm enforcement replaces rather than reinforces social norm enforcement. This finding is in line with predictions stemming from social-preference models, but it conflicts with expressive theories of law. It is important to note, however, that in the simple game situation at hand it is quite salient what is socially desirable and what is undesirable. One might conjecture to find support for expressive theories of law in more complicated environments. Regarding the composition of the other group members' contributions we find that (i) $j$ is punished less the more he contributes and (ii) is punished more, the more $i$ contributes; and (iii) $j$ is punished more in a group of high contributors than in a group of low contributors. The last observation implies that contributions trigger a negative externality on other group members' payoffs at the punishment stage of the game, as they ceteris paribus increase the magnitude of sanctions incurred for a given contribution level.

Contributions The next interesting step is to see how subjects' contribution decisions are affected by the introduction of non-deterrent legal sanctions. Figure 2 shows a box-plot of individuals' contribution to the public good. In treatment BASE, where only social sanctions are

\footnotetext{
${ }^{11}$ All these results (as well as those presented in Table 4 below) are robust when we control for self-reported risk attitudes and other individual characteristics (e.g., age, gender, etc.). Estimation results are available from the authors.
} 
possible, the mean contribution level is 11.8 (median: 12). In treatment LAW, where legal and social sanctions are effective, the mean is 15.1 (median: 17). The increase in contributions of $28 \%$ is highly significant (rank-sum test, $p=.0098$, two-sided). This treatment effect extends the results from Galbiati and Vertova (2008a, 2008b). They show that a mild law on its' own increases cooperation significantly. Our findings demonstrate that the effect is robust when the mild law is paired with decentralized punishment - even when the formal sanctioning institution crowds-out the informal one.

Figure 2: Contributions

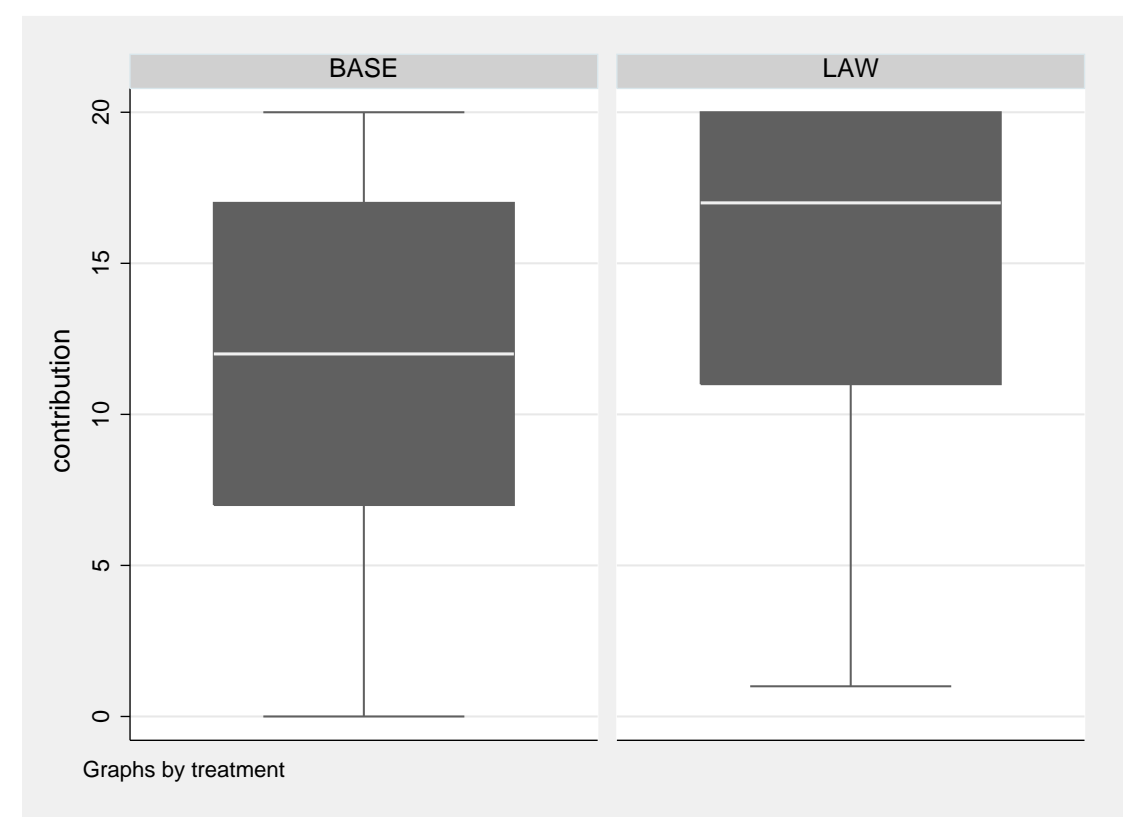

The observation that contributions increase in LAW is important. It reveals that the combination of centralized and decentralized sanctioning institutions is successful in enforcing cooperation - despite the crowding-out of social sanctions. Since our study was designed to analyze the impact of legal on social sanctions, we cannot exactly identify the reasons for the strong increase of subjects' contribution in LAw. In contrast to Galbiati and Vertova, who highlighted the coordination function of mild laws, our results point to steeper incentives from punishment. Recall, that the marginal social cum legal sanctions that are imposed for free-riding is higher in treatment LAW than in BASE. In fact, the point estimates from Table 2 suggest that the expected payoff impact 
from free-riding is positive in treatment BASE but slightly negative in LAW. ${ }^{12}$ Hence, contributing zero would still be the expected-payoff maximizing strategy in BASE (although with a very small payoff advantage) but not in LAw. This underlines that a society which manages to establish a mild law together with decentralized norm enforcement can arrive at a successful institutional setup. While Galbiati and Vertova (2008a) have found that mild legal sanctions per se fail to maintain high contributions in a repeated game, our results suggest that the combination of legal cum social sanctions should be more effective. It is due to future research to test this conjecture.

Welfare effect So far we have shown that the LAW treatment partially crowds-out social sanctions and that it increases the actual level of cooperation at the contribution-stage. To assess the overall welfare-impact of the treatment, we have to consider the realized legal sanctions as well as the decentralized sanctioning behavior for the actual contribution triple. In line with the above results, the data show a substantial crowding-out effect in the punishment decisions for the actual contribution-triples as well. The mean number of punishment points assigned declines from 0.71 in BASE to 0.30 in LAW. This drop of $57 \%$ is significant at the $5 \%$-level (rank-sum test, $p=.031$, two-sided). The pronounced difference is driven by two effects. On the one hand, the direct crowding-out effect that we demonstrated above leads to a reduction in social punishment - even when we keep the other's contributions constant. On the other hand, there is now an indirect effect as contribution levels are higher in LAW than in BASE. Since higher contributions lead to lower punishment, we observe a further decline in social sanctioning. This also implies that the actual welfare gain from introducing legal sanctions is larger than suggested by the analysis of the direct effect.

\begin{tabular}{lccc}
\hline \hline Mean Payoff & BASE & LAW & $\Delta$ \\
\hline Public good, $\pi^{I}$ & 27.10 & 29.08 & $+7 \%$ \\
Social sanctions, $\pi^{I I}$ & -8.51 & -3.60 & $-57 \%$ \\
Legal sanctions, $\pi^{I I I}$ & & -0.77 & \\
\hline Total payoff, $\Pi$ & 18.59 & 24.65 & $+33 \%$ \\
\hline \hline
\end{tabular}

Table 3: Payoff comparison between treatments

A summary of the payoff comparison is provided in Table 3. Taking (i) the increase in cooperation, (ii) the decline in the costs for (giving and receiving) decentralized punishment, as

\footnotetext{
${ }^{12}$ Based on the marginal effects from Table 2 (i.e., evaluated at the mean and conditional on being uncensored) and our parameter choices, we get $\partial\left(\pi_{i}^{I}+\pi_{i}^{I I}\right) / \partial c_{i}=-1+\alpha+(n-1) \gamma 0.06=-.06$ and $\partial\left(\pi_{i}^{I}+\pi_{i}^{I I}+\pi_{i}^{I I I}\right) / \partial c_{i}=$ $-1+\alpha+(n-1) \gamma 0.06+p s=.09$.
} 
well as (iii) the costs for (receiving) centralized sanctions together, the mean payoff in treatment LAW increases by $33 \%$ (as compared to BASE). This comparison does not account for the costs of the legal system. As long as the mild law can be implemented at reasonable costs, however, there is scope for potentially large welfare gains. If, for instance, the social costs for reducing an individual's payoffs by 1 token would be the same if it were via legal or via social sanctions (namely $\beta / \gamma=1 / 3$ ), the treatment would still achieve a net-welfare gain of $32 \%$.

\subsection{Within-subject comparison}

Introducing a mild law It seems natural to think of a situation where legal sanctions are introduced into an existing environments that features only social sanctions. This exogenous change $^{13}$ from an 'archaic' into a 'modern' society is captured in the first sequence of our experiment (see Table 1). In this sequence, subjects first faced treatment BASE and subsequently played treatment LAW (of course, without receiving any feedback in-between). This allows for a within-subject analysis of how the sanctioning behavior reacts to the introduction of a legal system.

As above, we first compare the social sanctions for the hypothetical contribution situations in the two treatments. The left panel of Figure 3 displays the sanctioning pattern in the hypothetical contribution situations for those subjects who first play treatment BASE and treatment LAW afterwards. This figure closely resembles what we have observed above (see Figure 1). The mean amount of punishment for different gaps $c_{i}-c_{j}$ in public-good contributions strongly reduces when the centralized sanctions are introduced. Decentralized punishment drops from .84 down to .70 , the difference now being highly significant in the non-parametric test (sign-rank test, comparing each subject's mean amount of punishment in BASE to the mean amount in LAW, $p=.0090$, two-sided). Hence, there is again a significant crowding-out of social sanctions by legal sanctions in the within-subject comparison, suggesting that the results from the between-comparison are robust. ${ }^{14}$

The same holds true regarding the analysis of contributions. After the introduction of legal sanctions, the mean contribution increases from 11.8 to 15.3 (sign-rank test, $p \leq 0.001$, two-sided).

\footnotetext{
${ }^{13}$ On the endogenous formation of institutions see Tyran and Feld (2006) and Kosfeld et al. (2009).

${ }^{14} \mathrm{~A}$ possible concern is that subjects may simply decrease their punishment from the first to the second treatment. The decline in sanctioning displayed in the left panel of Figure 3 may therefore also comprise a sequence effect. This point is further discussed below (see Table 4).
} 
Figure 3: Mean Punishment Patterns - Within-Subject Comparison

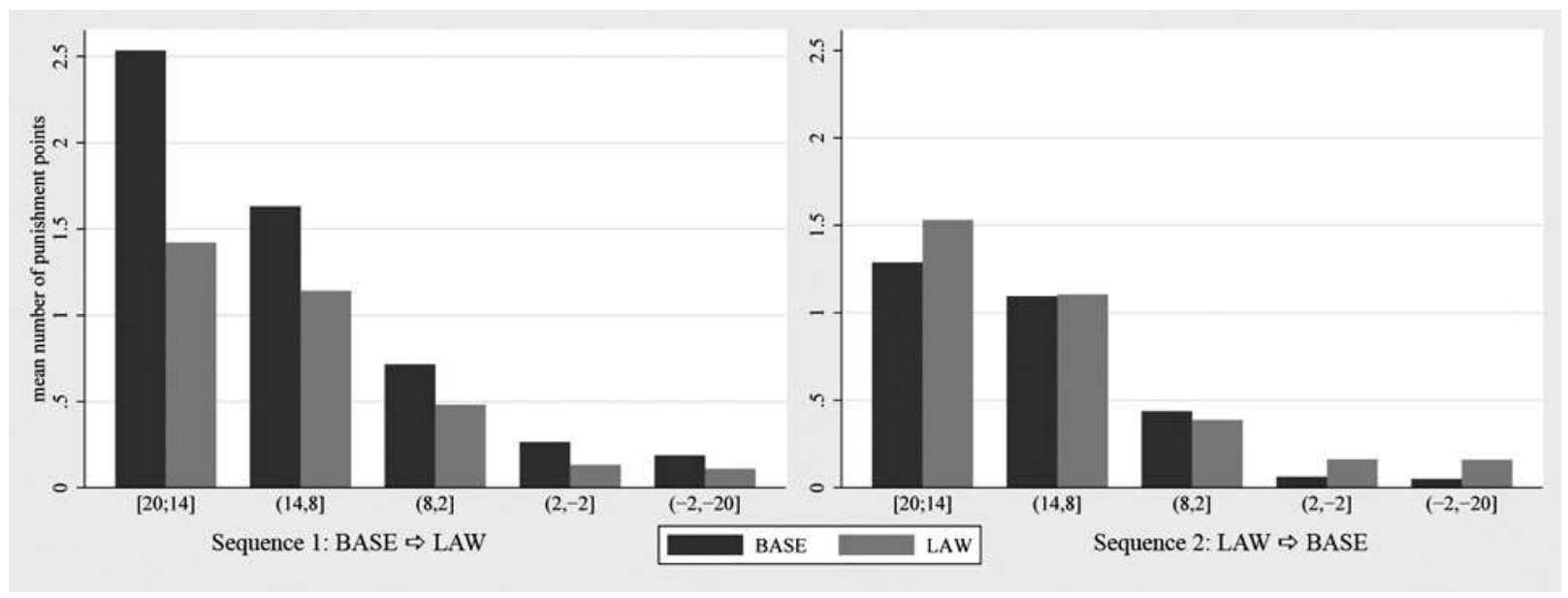

Thus, the crowding-out of social sanctions is again accompanied by an increase in cooperation.

Not surprisingly, we also observe a substantial decline in the decentralized punishment imposed on the actual contribution choices (from 2.12 to $1.21 ; p \leq 0.001$ ). Consequently, the introduction of a mild law yields a $28 \%$ increase in the average payoff, which coincides qualitatively and quantitatively with the effects displayed in Table 3.

Removing a legal system Contrary to the introduction of mild laws, one might also ask how removing an initially existing centralized institution affects decentralized norm enforcement. Are social sanctioning levels going to remain at modest levels or will they increase again? To address this question we had subjects play the reversed treatment-order, i.e., those who first faced treatment LAW did subsequently play treatment BASE. The punishment behavior for this second sequence is displayed in the right panel of Figure 3.

In contrast to our previous findings, we observe only minor changes in social sanctions in this treatment order. Subjects who started in treatment LAW assign 0.69 points on average, and subsequently 0.53 in treatment BASE. The decline is significant at a 5\%-level (sign-rank test, $p=.0112$, two-sided). To assess this effect, note first that the average punishment in the LAW treatment is virtually identical to the one for the alternative treatment order $(0.70$ and 0.69 for Sequence 1 and 2, respectively). However, moving from LAW to BASE, decentralized punishment declines even further. Hence, in Sequence 2, social sanctions do not fill the gap which is left after removing the mild law. One can think of at least two possible interpretations of this observation. On the one hand, the crowding-out effect might spill over into the second treatment BASE: once 
subjects start from a situation where norm enforcement is partially delegated to a centralized institution, they might be less willing to take over this role again. ${ }^{15}$ On the other hand, there might be a significant order effect, resulting in a decline in the level of punishment from the first to the second experiment. In either case, the evidence clearly indicates that removing the mild law resulted in a drop in overall norm enforcement. The question then arises to which extent this is also reflected in cooperation levels.

In line with intuition, we indeed observe a decline in cooperation. The average contribution significantly drops after removing the legal sanctioning mechanism, from 15.1 in LAW to 13.1 in BASE (sign-rank test, $p=.0178$, two-sided). The resulting decline in the payoff from stage I is compensated by a smaller amount of social sanctions in BASE, such that removing the legal sanctions has practically no effect on the total payoff (the relative change in average payoff is $0.003 \%)$. While the between- as well as the within-subject comparison for Sequence 1 document that centralized institutions significantly increases payoffs, this last finding suggests that removing them might not necessarily be harmful to overall welfare. It is up to future research to test the effects from establishing and then abolishing legal sanctions in a dynamic setup.

Full sample analysis We conclude the results-section by applying the parametric analysis of the decentralized punishment choice from above (see Table 2) to our full sample, i.e., including the data from the first as well as the second treatment (see Table 1). The regression analysis confirms and extends our previous findings. First, the LAW treatment results in a crowding-out of social sanctions. As we pool all our data, the effect is now highly significant. At the same time, however, the direct effect is quantitatively less strong than the one found before. This is mainly driven by the fact that the between-treatment differences for the treatments played second are less pronounced. Second, subject $i$ 's punishment of $j$ is the stronger, the larger the difference in their contributions is, and the higher the other player's contributions are. Third, there is no interaction effect between the treatment and the contribution difference $c_{i}-c_{j}$ (Column 4 ). Hence, the crowding-out is in levels rather than on the margin. Finally, the regressions point to a significant sequence effect: in line with our interpretation of the order effect for Sequence 2, there is significantly less sanctioning in the second treatment.

\footnotetext{
${ }^{15}$ Gächter et al. (2009) report a similar finding in the context of gift-exchange games: exposing workers to explicit performance incentives significantly reduces voluntary cooperation in subsequent trust-contracts.
} 
Table 4: Random-effects Tobit regression: Marginal effects on social sanctions

\begin{tabular}{|c|c|c|c|c|}
\hline \multicolumn{5}{|c|}{ Dependent variable: $d_{i j}$} \\
\hline & (1) & (2) & (3) & (4) \\
\hline LAW & $\begin{array}{c}0.028 \\
(0.021)\end{array}$ & $\begin{array}{c}-0.074^{* * *} \\
(0.016)\end{array}$ & $\begin{array}{c}-0.077^{* * *} \\
(0.015)\end{array}$ & $\begin{array}{c}-0.060^{* * *} \\
(0.022)\end{array}$ \\
\hline$c_{i}-c_{j}$ & & $\begin{array}{c}0.058^{* * *} \\
(0.003)\end{array}$ & $\begin{array}{c}0.060^{* * * *} \\
(0.003)\end{array}$ & $\begin{array}{c}0.061^{* * *} \\
(0.004)\end{array}$ \\
\hline$\left(c_{i}-c_{j}\right) \times L A W$ & & & & $\begin{array}{l}-0.002 \\
(0.002)\end{array}$ \\
\hline$c_{k, l}$ & & & $\begin{array}{c}0.010^{* * *} \\
(0.001)\end{array}$ & $\begin{array}{c}0.010^{* * *} \\
(0.001)\end{array}$ \\
\hline$t$ & $\begin{array}{c}-0.008^{* *} \\
(0.003)\end{array}$ & $\begin{array}{c}-0.004^{*} \\
(0.003)\end{array}$ & $\begin{array}{c}-0.005^{*} \\
(0.002)\end{array}$ & $\begin{array}{c}-0.005^{*} \\
(0.003)\end{array}$ \\
\hline $2^{\text {nd }}$ Treatment & $\begin{array}{c}-0.119^{* * *} \\
(0.021)\end{array}$ & $\begin{array}{c}-0.158^{* * *} \\
(0.017)\end{array}$ & $\begin{array}{c}-0.159^{* * *} \\
(0.017)\end{array}$ & $\begin{array}{c}-0.159^{* * *} \\
(0.017)\end{array}$ \\
\hline Log-likelihood & -5617 & -4391 & -4365 & -4365 \\
\hline Observations & 5640 & 5640 & 5640 & 5640 \\
\hline
\end{tabular}

Notes: The table displays the marginal effects evaluated at the mean (conditional on being uncensored) from random effects Tobit regressions. The dependent variable is the number of punishment points assigned from $i$ to $j, d_{i j}$. The sample covers all punishment choices for hypothetical triples in the initial and the subsequent treatment. $2^{\text {nd }}$ Treatment is a dummy, indicating whether the observation is from the second experiment. All other regressors are as described in Table 2. Standard errors are in parentheses. Level of significance: ${ }^{*} p<0.1,{ }^{* *} p<0.05,{ }^{* * *} p<0.01$.

\section{Concluding discussion}

This paper studied the link between centralized and decentralized punishment in a public-goods game. We developed a novel experimental approach to elicit subjects' punishment behavior via the strategy method. This allowed us to identify direct and indirect effects from legal on social sanctions. Centralized and decentralized norm enforcement turned out to be substitutes in our experiment: social sanctions were partially crowded-out by legal sanctions. While individuals imposed less punishment on average, the marginal social cum legal sanctions faced by a free-rider were higher in the presence of a 'mild law'. In line with this observation, we found that the legal sanctions triggered a substantial increase in public-good contributions - despite the crowding-out of decentralized punishment. Thus, a higher level of cooperation was obtained at lower costs of social sanctioning. Consequently, the implicit delegation of norm enforcement to a formal, centralized institution allowed for a significant increase in overall welfare. The combination of 
mild laws and social sanctions therefore appears to be a successful institutional arrangement to enforce compliance.

From the perspective of expressive theories of law, our results appear surprising at first sight. One might have conjectured that the introduction of a legal system crowds-in social sanctions, as the law shapes player's perceptions about what is socially desirable and undesirable. In the context of our public-goods game, however, it seems that there was little ambiguity about what to consider 'good' and 'bad' conduct. Already in the absence of legal sanctions, subjects' punishment behavior was clearly targeted at free-riders and we observed hardly any 'anti-social punishment'. Hence, there was little scope for the law to serve as a coordination device for punishment. In future research, it would be interesting to see if one finds support for expressive theories of law in more complex environments, where the distinction between pro- and anti-social behavior is less salient.

While our study establishes the first experimental evidence on the interplay of legal and social norm enforcement, there are several avenues for future research. We observed that the exogenous shift from an 'archaic' society (where only decentralized norm enforcement is possible) towards a 'modern' society (with a formalized enforcement institution) had a clear impact on players' punishment and contribution choices. In the future, we want to assess the importance of the different channels that can shape cooperation, i.e., the immediate effect of legal sanctions as well as the law's effect on subjects' expectations regarding the other players' contributions and sanctions. A promising first step in this agenda would rely on an experimental variation of the 'content' of the law and its formal enforcement (fines, sanction risk, etc.). A further important task is to shed light on the long-run effects from the combination of formal and informal norm enforcement. Will cooperation sustain when legal and social sanctions are available? What if players are given the possibility to shape these institutions endogenously? Research along these lines promises to provide valuable insights into the functioning of modern societies and will help to increase our understanding of effective enforcement institution. 


\section{References}

Becker, G. (2007), Why so Little Tax Evasion? The Becker-Posner Blog, November 25, 2007.

Bosman R. and F. van Winden (2002), Emotional Hazard in a Power-to-take Experiment, Economic Journal, Vol. 112, pp. 147-169.

Brandts, J. and G. Charness (2000), Hot vs. Cold: Sequential Responses and Preference Stability in Experimental Games, Experimental Economics, Vol. 2, pp. 227-238.

Carpenter, J. P. (2007), The Demand for Punishment, Journal of Economic Behavior and Organization, Vol. 62, pp. 522-542.

Cohen, M. (2000), Monitoring and enforcement of environmental policy, in: H. Folmer and T. Tietenberg (Eds.), The International Yearbook of Environmental and Resource Economics 1999/2000. Edward Elgar Publishers.

Cooter, R. D. (1998), Expressive Law and Economics, Journal of Legal Studies, Vol. 27, pp. 585608.

Ellickson, R. C. (1998), Law and Economics Discovers Social Norms, Journal of Legal Studies, Vol. 27, pp. 537-552.

Falk, A., E. Fehr and U. Fischbacher (2005), Driving Forces behind informal sanctions, Econometrica, Vol. 73, pp. 2017-2030.

Fehr, E. and S. Gächter (2000), Cooperation and Punishment in Public Goods Experiments, American Economic Review, Vol. 90, pp. 980-994.

Fehr, E. and S. Gächter (2002), Altruistic Punishment in Humans, Nature, Vol. 415, pp. 137-140.

Fehr, E. and K. M. Schmidt (1999), A Theory of Fairness, Competition, and Cooperation, The Quarterly Journal of Economics, Vol. 114, pp. 817-868.

Fehr, E. and K. M. Schmidt (2006), The Economics of Fairness, Reciprocity and Altruism Experimental Evidence and New Theories, in: Handbook on the Economics of Giving, Reciprocity and Altruism, Elsevier.

Fischbacher, U. (2007), z-Tree: Zurich Toolbox for Ready-made Economic Experiments, Experimental Economics, Vol. 10, pp. 171-178.

Fischbacher, U. and S. Gächter (2009), Social Preferences, Beliefs, and the Dynamics of Free Riding in Public Good Experiments, American Economic Review, forthcoming.

Fischbacher, U., S. Gächter and E. Fehr (2001), Are People Conditionally Cooperative? Evidence from a Public Goods Experiment, Economics Letters, Vol. 71, pp. 397-404.

Gächter, S., E. Kessler and M. Königstein (2009), Performance Incentives and the dynamics of voluntary cooperation, mimeo.

Gächter, S., E. Renner and M. Sefton (2008), The Long-Run Benefits of Punishment, Science Vol. 322, p. 1510.

Galbiati, R. and P. Vertova (2008a), Obligations and Cooperative Behaviour in Public Good Games, Games and Economic Behavior, Vol. 64, pp. 146-170.

Galbiati, R. and P. Vertova (2008b), How Laws Affect Behaviour, Working Paper, University of Paris Ouest. 
Greiner, B. (2004), The Online Recruitment System ORSEE 2.0, Working Paper Series in Economics, University of Cologne.

Gürerk, Ö., B. Irlenbusch and B. Rockenbach (2006), The Competitive Advantage of Sanctioning Institutions, Science, Vol. 312, pp. 108-111.

Hopfensitz, A. and E. Reuben (2009), The Importance of Emotions for the Effectiveness of Social Punishment, Economic Journal, Vol. 119, pp. 1534-1559.

Herrmann, B., C. Thöni and S. Gächter (2008), Antisocial Punishment Across Societies, Science, Vol. 319, pp. 1362-1367.

Hörisch, H. and C. Strassmair (2008), An Experimental Test of the Deterrence Hypothesis. SFB TR/15 Working Paper 229.

Kosfeld, M., A. Okada and A. Riedl (2009), Institution Formation in Public Goods Games, American Economic Review, Vol. 99, pp. 1335-1355.

Masclet, D., C. Noussair, S. Tucker and M.-C. Villeval (2003), Monetary and Nonmonetary Punishment in the Voluntary Contributions Mechanism, American Economic Review, Vol. 93, pp. 366380 .

McAdams, R. (2000), An Attitudinal Theory of Expressive Law, Oregon Law Review, Vol. 79, pp. 339-390.

Meares, T. L., N. Katyal and D. M. Kahan (2004), Updating the Study of Punishment, Stanford Law Review, Vol. 56, pp. 1171-1210.

Nikiforakis, N. and H. T. Normann (2008), A Comparative-Statics Analysis of Punishment in Public-Good Experiments, Experimental Economics, Vol. 11, pp. 358-369.

Posner, R. A. (2000), Law and Social Norms, Cambridge: Harvard University Press.

Rege, M. (2004), Social Norms and Private Provision of Public Goods, Journal of Public Economic Theory, Vol. 6, pp. 65-77.

Selten, R. (1967), Die Strategiemethode zur Erforschung des eingeschränkt rationalen Verhaltens im Rahmen eines Oligopolexperiments, pp. 136-168, in: H. Sauermann (Ed.), Beiträge zur experimentellen Wirtschaftsforschung, Tübingen: J.C.B. Mohr.

Trautmann, S. T. (2009), A Tractable Model of Process Fairness under Risk, Journal of Economic Psychology, forthcoming.

Traxler, C. and J. Winter (2009), Survey Evidence on Conditional Norm Enforcement, Max Planck Institute for Research on Collective Goods, Working Paper 2009-03.

Tyran, J.-R. and L. P. Feld (2006), Achieving Compliance when Legal Sanctions are Non-deterrent, Scandinavian Journal of Economics, Vol. 108, pp. 135-156. 


\section{Appendix I: Contribution Triplets}

In the following, we list the contribution triples that were used within each combination of $c^{L}, c^{M}$ and $c^{H}$. Before the experiment, these $10 \times 8$ triples were randomly generated by sampling with replacement from the corresponding sets $c^{L}, c^{M}, c^{H}$. Each player then faced a randomly selected triple within each combination 1 - 10. If the selected triple would by chance correspond to the real triple, the subject would not face this situation but instead another one of the pre-defined contribution triples for the corresponding combination.

(1) $\left(c^{L}, c^{L}, c^{L}\right):(0,0,0),(0,2,3),(1,1,3),(1,2,2),(1,2,3),(1,2,4),(1,3,3),(1,3,4)$

(2) $\left(c^{L}, c^{L}, c^{M}\right):(0,1,5),(0,2,8),(0,2,14),(1,2,10),(1,2,12),(1,3,14),(2,2,6),(2,3,12)$

(3) $\left(c^{L}, c^{L}, c^{H}\right):(0,3,18),(1,2,20),(1,3,19),(1,4,20),(2,2,18),(2,2,19),(3,3,18),(4,4,17)$

(4) $\left(c^{L}, c^{M}, c^{M}\right):(0,9,11),(0,5,12),(0,13,14),(1,10,15),(2,6,8),(2,9,11),(2,10,15),(3,13,14)$

(5) $\left(c^{L}, c^{M}, c^{H}\right):(0,6,19),(0,14,17),(2,6,17),(2,8,20),(2,11,19),(3,7,18),(4,8,17),(4,10,20)$

(6) $\left(c^{L}, c^{H}, c^{H}\right):(0,18,19),(1,19,19),(2,18,19),(2,18,20),(2,19,19),(3,18,20),(3,19,19),(4,19,20)$

(7) $\left(c^{M}, c^{M}, c^{M}\right):(5,7,12),(5,14,16),(6,6,9),(6,10,10),(7,8,9),(7,10,13),(7,14,16),(8,9,11)$

(8) $\left(c^{M}, c^{M}, c^{H}\right):(5,5,17),(5,8,18),(6,11,20),(8,15,17),(9,12,18),(9,15,18),(11,15,19),(12,15,19)$

(9) $\left(c^{M}, c^{H}, c^{H}\right):(5,18,20),(7,18,19),(9,18,20),(11,17,17),(12,17,18),(12,18,18),(14,17,20),(15,17,19)$

(10) $\left(c^{H}, c^{H}, c^{H}\right):(17,17,19),(17,18,19),(17,18,20),(17,19,19),(17,19,20),(18,18,19),(18,18,20),(20,20,20)$

\section{Appendix II: Instructions}

Reported below. 
THESE ARE THE TRANSLATIONS OF THE GERMAN INSTRUCTIONS FOR TREATMENT LAW. INSTRUCTIONS IN TREATMENT BASE WERE IDENTICAL EXCEPT FOR THE PARTS CONCERNING THE THIRD STAGE.

\section{General explanations to the participants}

You are now participating in an economic experiment. Today's experiment consists of more than one part, the parts being independent from one another. If you read the following explanations carefully, you'll be able to earn a considerable amount of money - depending on your decisions and those of the other participants. Thus, it is important to read these instructions very carefully.

The instructions you received are for your private information only. It is absolutely prohibited to communicate with the other participants during the experiment. Should you have any questions, please ask us. If you violate this rule, you will be dismissed from the experiment and forfeit all payments

The experimental payoffs will be calculated in Taler. The total amount of Taler that you have accumulated during the experiment will be converted into Euro and paid to you in cash at the end of the experiment. You will be informed about the exchange rate from Taler to Euro at the beginning of each part of the experiment.

The experiment is divided into periods. In each period, participants are divided into groups of four. You will therefore be in a group with 3 other participants. In each period, the composition of the groups will change. Therefore, participants cannot be identified across periods.

Each period consists of 3 stages. On stage 1, you have to decide how many Taler to contribute to a project. On stage 2, you learn about the others' contributions and then have to decide, if, resp. by how much, you want to reduce the others' income from stage 1 . On stage 3 , a random device decides if a participant's income is reduced further.

\section{Detailed information about a period}

\section{The first stage:}

At the beginning of each period each participant receives 20 Taler. We call this his or her endowment. Your task is to decide how to use your endowment. You have to decide how many of the 20 tokens you want to contribute to a project and how many of them to put on your private account. 
Income from your private account:

For each Taler you put on your private account, you earn one Taler. For example, if you put 20 Taler on your private account (thus contributing zero Taler to the project), you would earn 20 Taler from your private account. If you, e.g., would contribute 12 Taler to the project (thus putting 8 Taler on your private account), your income from the private account would be 8 Taler. Nobody but you receives Taler from your private account.

Income from the project:

For each Taler contributed to the project, you (and each other participant in your group) earn 0.4 Taler. Each participant's income from the project is thus given by:

\section{Income from the project $=$ Sum of contributions to the project $x 0.4$}

Example: If the sum of contributions would equal 20 Taler (e.g., if you and the other three participants in your group would contribute 5 Taler each), you and everyone else in your group would receive an income of $20 \times 0.4=8$ Taler from the project. If the sum of contributions would equal 10 Taler, you and everyone else in your group would earn $10 \times 0.4=4$ Taler from the project.

\section{Income at the end of stage 1:}

Your income at the end of stage 1 consists of your income from your private account and the income from the project:

Income from the private account $(=20$-your contribution)

+ Income from the project $(=0.4 \times$ sum of contributions to the project)

Income at the end of stage 1

Let us illustrate how to calculate your income at the end of stage 1 using an example:

You and the other participants in your group contribute 15 Taler each. The sum of contributions thus equals $15+15+15+15=60$ Taler. Your income at the end of stage 1 would then be given by:

5 Taler from your private account $+0.4 \times 60$ Taler from the project $=5+24=29$ Taler

If you would have contributed, e.g., 0 Taler instead, the sum of contributions would equal $15+15+15+0=45$ Taler. Thus, your income at the end of stage 1 would then be given by:

20 Taler from your private account $+0.4 \times 45$ Taler from the project $=20+18=38$ Taler

The others' incomes at the end of stage 1 are calculated accordingly. 


\section{The second stage:}

At the beginning of the second stage, you are informed about the contribution decisions of the other participants in your group. You can then reduce or leave constant the income from stage 1 of each participant in your group. The other participants can also reduce your income if they wish to.

In order to reduce the income of a participant, you have to assign points to him. Each point assigned reduces the other's income by 3 Taler. If you assign 1 point, you reduce his or her income by 3 Taler. If you assign 2 points, you reduce his or her income by 6 Taler etc. If you do not want to change the other's income, you assign 0 points.

The more points you assign to a participant, the higher is his or her income reduction. At the same time, however, each point that you assign reduces your own income as well. Each point assigned reduces your own income by 1 Taler. For instance, if you assign 2 points, you reduce your own income by 2 Taler. If you assign 4 points, you reduce your own income by 4 Taler; if you assign 0 points, you do not incur any costs.

You have to decide for each participant in your group how many points you want to assign to him or her. You can assign up to 10 points per participant.

By how much a participant's income is reduced in total depends on the sum of received points. If somebody, for instance, receives 1,0 and 2 point from the others, his or her income will be reduced by $(1+0+2) \times 3=9$ Taler. At the same time, the others have to bear the cost for assigning points of 1,0 , resp. 2 Taler.

\section{The third stage:}

On stage 3 , a random device decides if a participant's income is reduced further. Each participant is selected with a probability of $12.5 \%$. In each group, one participant is selected at most. (A probability of $12.5 \%$ can be illustrated as follows: You throw an 8-sided dice. Your income will be further reduced if the dice shows a 1.)

If you are the one who is randomly selected, your income will be reduced by 1.2 times the amount you have put on your private account on stage 1. The same holds true for the other participants.

For instance, if you contributed 5 Taler on stage 1, thus putting 15 Taler on your private account, your income might probably be reduced by

$1.2 \times 15$ Taler $=18$ Taler

For instance, if you contributed 19 Taler on stage 1, thus putting 1 Taler on your private account, your income might probably be reduced by

$1.2 \times 1$ Taler $=1.20$ Taler

If you contributed 20 Taler on stage 1, your income will not be reduced at all on stage 3 . 
Consider that the events on stage 3 do not depend on the decisions made on stage 2. That is, the probability that one's income is further reduced is not affected by the number of points assigned or received on stage 2. Furthermore, consider that at the time you are assigning points on stage 2, you do not know whether the income of a participant will be reduced further. Yet, you know the probability with which this is going to happen (namely, 12.5\%).

\section{Your Period Payoff:}

Your payoff in each period is thus given by:

Income from stage 1

- Reductions for points received on stage 2

- Costs for points assigned to others on stage 2

- reductions on stage 3 if you are randomly selected

Period Payoff 


\section{Additional explanations for the first part of the experiment}

The exchange rate in the first part of the experiment is:

\section{Taler $=20$ Eurocent}

In addition, each participant will receive a show-up fee of 20 Taler (=4 Euro) for showing up on time today.

The first part of the experiment consists of a single period. In the beginning, the proceeding is as described above: You will be randomly matched into groups of four. On stage 1, you have to decide how many Taler you want to contribute to the project, and how many Taler you want to put on your private account.

On the second stage, you will be facing a series of several different decision situations. Each decision situation consists of a combination of possible contributions of the other participants in your group. That is, it might be that the three contributions in the decision situation are fictitious rather than being the actual contributions of the other three participants. As described above, after observing the contributions you have to decide how many points you want to assign to each of the three participants in this particular decision situation.

After you have assigned points in the present decision situation, you will be shown another combination of (possibly fictitious) contributions of the other three participants in your group. Also for this decision situation, you have to assign points, ...

In total, you will be facing eleven decision situations. Ten of the eleven decision situations are fictitious. Yet, in exactly one decision situation you will be facing the actual contribution decisions of the other three participants in your group. How many points you actually assign to the other three participants, as well as your actual payoff on stage 3 , will only be determined by the decisions made in the actual decision situation. The decisions made by you in the ten fictitious decision situations do not affect the others' income or your income. Of course, when you are deciding on how many points to assign in a specific decision situation, you do not know if the contributions shown to you are the actual ones or whether they are only fictitious. Therefore, you have to consider each decision carefully and seriously, because each decision situation might potentially become relevant for your payoff.

[TREATMENT LAW ONLY:] Stage 3 will proceed as described above. With a probability of 12.5\%, the income of each player will be reduced further. In each group, one person will be selected at most.

Do you have any questions? If so, please raise your hand. 